\title{
Antimicrobial Efficacy of Mineral Trioxide Aggregate against Therapy Resistant Endodontic Microorganisms
}

\author{
MLA BANU $^{\mathrm{a}}$, AKM BASHAR ${ }^{\mathrm{b}}, \mathrm{MR}^{\mathrm{H}} \mathrm{HOWLADER}^{\mathrm{c}}$, MS ALAM $^{\mathrm{d}}$, MA HUSSAIN $^{\mathrm{e}}$
}

Summary:

Microorganisms, usually from the dental caries, are the main sources of diseases in dental pulp (root canals) and periapical region. Facultative bacteria and fungi have been identified in therapy resistant persistent endodontic infection. The objectives of this study was to evaluate the antimicrobial efficacy of Mineral Tri Oxide Aggregate (MTA) against therapy resistant endodontic microorganisms. The efficacy of MTA was also compared with that of calcium hydroxide. Six standard bacterial stains were used: Staphylococcus aureus, Pseudomonas aeruginosa, Escherichia coli, bacillus subtilis, Candida albicans and Enterococcus faecalis. The agar diffusion method on MullerHilton media was employed. The plates containing media were inoculated with the specified bacterial suspensions. Two standard holes were prepared on each microorganism inoculated plate with a copper puncher and one hole was completely filled with MTA \& the other with $\mathrm{Ca}(\mathrm{OH})_{2}$. The plates were then kept at environmental temperature for one hour to ensure prediffusion and then incubated at $37^{\circ} \mathrm{C}$ for 24 hours. After 24 hours, the diameters of inhibition zones were measured. Tests were replicated for thirty times for each sample and mean values were taken. Zone of inhibition as measured for MTA and Ca

Introduction:

Success of endodontic treatment and re treatment depends on elimination of bacteria and their substrate

a. Dr. Mst. Laila Akter Banu, Assistant Professor, Dept. of Conservative Dentistry \& Endodontics, Dhaka Dental College, Mirpur -14

b. Dr. A.K.M. Bashar, Assistant Professor, Dept. of Conservative Dentistry \& Endodontics, BSMMU, Shahbag, Dhaka

c. Dr. Md Mujibur Rahman Howlader, Associate Professor, Dept. of Conservative Dentistry \& Endodontics, BSMMU, Shahbag, Dhaka

d. Prof. Md Shamsul Alam, Professor \& Chairman, Department of Conservative Dentistry \& Endodontics, BSMMU, Shahbag, Dhaka

e. Prof. Md. Ashraf Hussain, Professor, Department of Conservative Dentistry, Pioneer Dental College, Dhaka

Address of Correspondence: Dr Mst. Laila Akter Banu, Assistant Professor, Department of Conservative Dentistry \& Endodontics, Room no 322, ${ }^{\text {nd }}$ Floor,hospital building, Dhaka Dental College, Mirpur -14, Dhaka, cell: 01732770060, email: fahmidasheema@gmail.com

Received: 22 January, 2014

Accepted: 8 January, 2015
$(\mathrm{OH})_{2}$ were statistically analyzed with Student's t-Test and Post Hoc Games Howell Test and were presented as mean \pm SD to compare of efficacy of MTA and calcium hydroxide on different microorganisms. Both MTA and $\mathrm{Ca}(\mathrm{OH})_{2}$ were found to produce zone of inhibition against Staphylococcus aureus (ATCC 25923), Pseudomonas aeruginosa (ATCC 27853), , Bacillus subtilis (BTCC 17), and Candida albicans (BTCC 493). MTA showed highest activity against $S$. aureus and lowest activity against $P$. aeruginosa which was similar to the activity range of $\mathrm{Ca}(\mathrm{OH})_{2}$ against the mentioned organisms. But both of them failed to produce any activity against $E$. coli and. $E$. faecalis. MTA was found to produce a lower efficacy than $\mathrm{Ca}(\mathrm{OH})_{2}$ while comparing the zone of inhibition between them and statistically it was significant. Mineral Tri Oxide Aggregate (MTA) showed antimicrobial efficacy against some therapy resistant microorganisms but it did not show antimicrobial efficacy against Escherichia coli and Enterococcus faecalis. MTA was found to produce a lower antimicrobial efficacy than $\mathrm{Ca}(\mathrm{OH})_{2}$.

Keywords: Mineral Tri Oxide Aggregate (MTA), Calcium hydroxide, antimicrobial efficacy.

(J Banagladesh Coll Phys Surg 2015; 33: 140-145)

from the root canal ${ }^{1}$. Intra-canal medicaments have been long used to control the pulpal and periapical infection in adjunct with biomechanical preparation. Therefore importance of antimicrobial medicaments in root canal therapy can not be over looked, because asepsis and sterilization in root canal environment can not be accomplished only by biomechanical preparation. So there has been a continuous search for new endodontic medicaments that present an ideal combination of good mechanical, physiochemical and biological properties.

Calcium hydroxide which has been used as an root canal medicament, sometimes found to be resistant in failed endodontic cases, especially in presence of certain resistant microorganism like Enterococci faecalis, E.coli etc. $^{2}$ Because of relative inefficient activity of calcium hydroxide, concerning the treatment of persistent infection cases, new endodontic materials search has been even more incessant.

Mineral Trioxide Aggregate or MTA is a new promising material, have shown a significant improvement over other materials in endodontics. Perforation, pathological 
incomplete root formation, periapical surgery, resorption etc. are often associated with failed or resistant endodontic cases, in which situation MTA has been proven as most effective repairing restorative material. 3-7 But regarding these situations, the antimicrobial efficacy of MTA especially against resistant microorganisms has not been clarified yet. Therefore the objective of this study is to evaluation of antimicrobial efficacy of Mineral Trioxide Aggregate on resistant endodontic microorganisms.

Furthermore the antimicrobial efficacy of MTA was also compared with that of calcium hydroxide.

\section{Materials and Methods:}

The prospective comparative study was done in the Department of Conservative Dentistry and Endodontics, and the Department of Microbiology and Immunology, Bangabundhu Sheikh Mujib Medical University Hospital from January 2006 to December 2007. Staphylococcus aureus (ATCC 25923), Pseudomonas aeruginosa (ATCC 27853), Escherichia coli ( ATCC 25922), Bacillus subtilis (BTCC 17 ), Candida albicans (BTCC 493) and Enterococcus faecalis (clinically isolated) were collected and preserved in crio vial with $20 \%$ glycerin broth and stored in liquid nitrogen at -196 ${ }^{0} \mathrm{C}$ temperature . Mueller Hinton agar media was poured in sterilized Petri Dishes and left till the media turned into gel form. Prepared potato dextrose media was collected and preserved in the same manner.

All the Prepared dishes were stored in refrigerator at $4^{0} \mathrm{C}$ until use. Immediately before inoculation, all the media containing plates were dried in dryer to make moisture free.

From the collected microbial specimens, using a sterilized swab, a lawn of single microbiological strain other than Candida albicans were taken and spreaded over a sterilized Mueller Hinton Plate. Candida albicans was spreaded over a sterilized potato dextrose agar media. All the plates were incubated for 24 hours at 37ÚC in incubator. Different microbiological strains were subcultured in different plates. A standard microbiological suspension was prepared compare with 0.5 McFarland Scale. (0.5 McFarland Scale $\left.=1.5 \times 10^{8} \mathrm{CFU}\right)$. The dried media in Petri dish was then inoculated with the prepared standard suspension of 0.5 McFarland Scale by sterile swab stick (Fig.-1).

Now two standard holes of $3 \mathrm{~mm}$ diameter and $4 \mathrm{~mm}$ depth were prepared on each individual micro organism inoculated plate with a copper puncher (Fig.-2). Mineral trioxide aggregate paste (Pro root MTA, Dentsply, Tulsa,

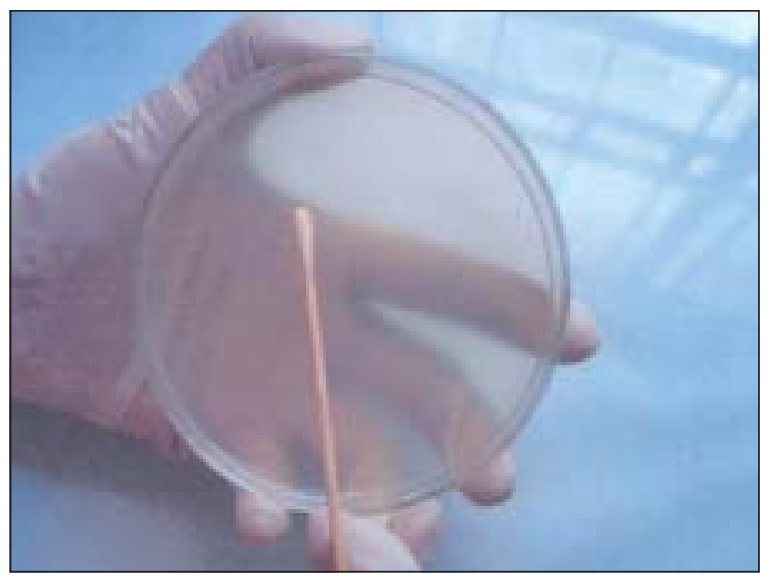

Fig.-1: Organism being inoculated on Muller Hilton media

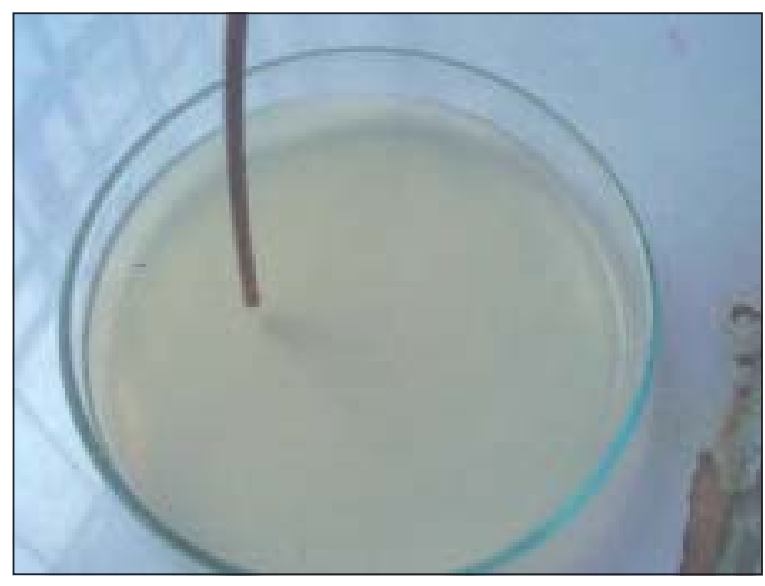

Fig.-2: Punching of media with copper puncher

USA) or MTA paste was made in a creamy consistency. One prepared hole in inoculated media was then completely filled immediately by MTA following its preparation (Fig.-3). Calcium hydroxide paste was directly poured into another hole from its tube with the help of a needle supplied by manufacturer (Fig.-4). All the micro organism inoculated plates were maintained at room temperature for 1 hour to allow pre diffusion of the materials, and then incubated at $37^{\circ} \mathrm{C}$ for 24 hours. 


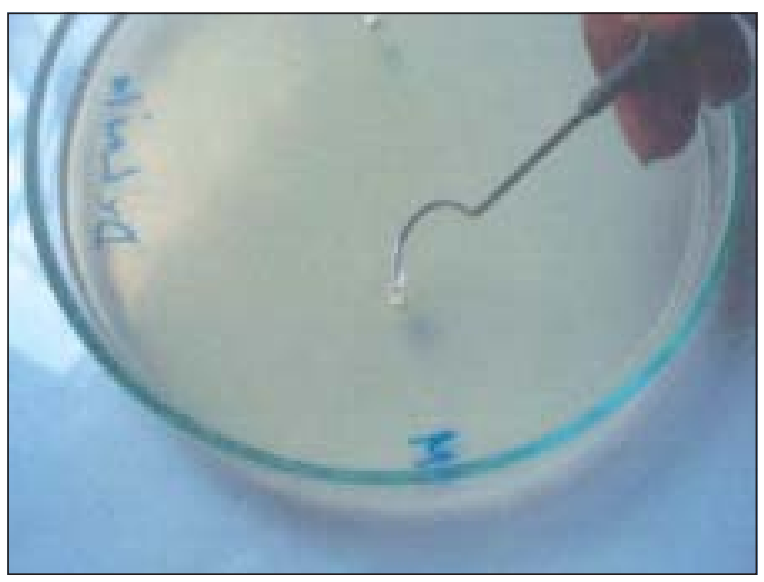

Fig.-3: Placement of prepared MTA into the punched cavity on organism inoculated media

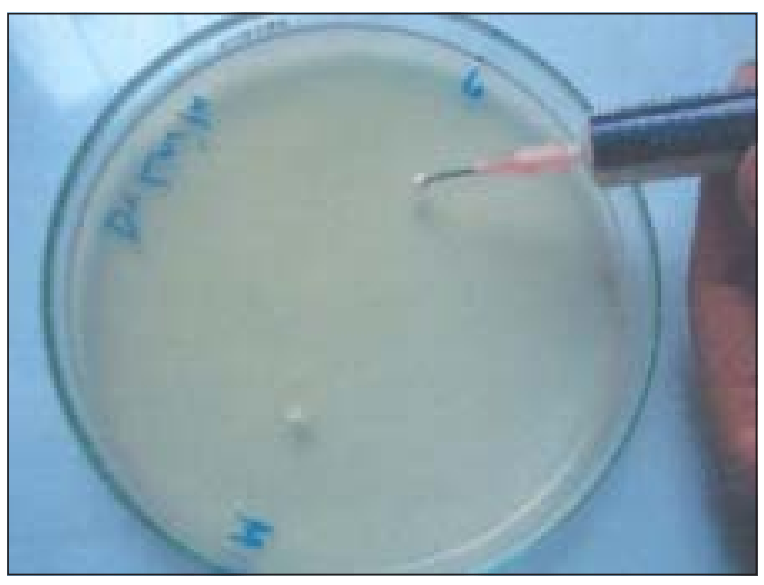

Fig.-4: Placement of $\mathrm{Ca}(\mathrm{OH})_{2}$ into the punched cavity on organism inoculated media

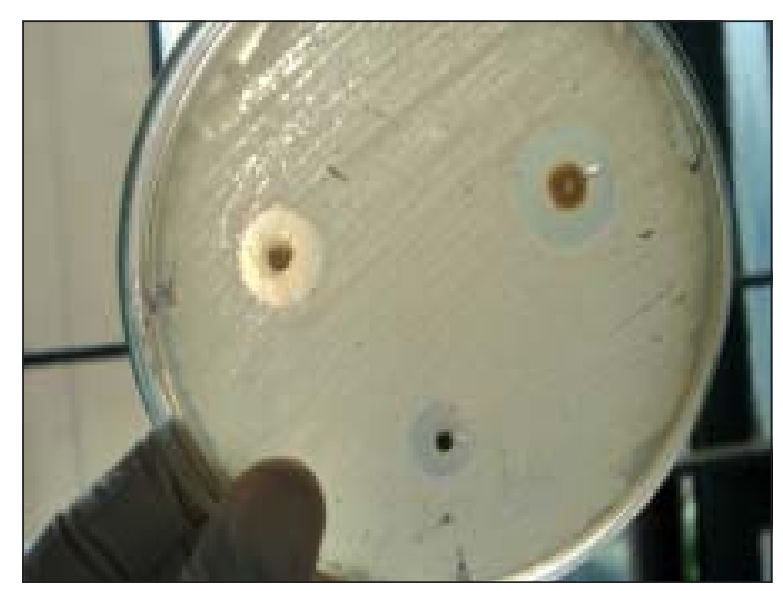

Fig.-5: Zone of Inhibition on Muller Hilton media
After 24 hours, plates were taken out of the incubator and observed for formation of zones of microbial inhibition. The zones were then measured with a millimeter ruler with accuracy of $0.5 \mathrm{~mm}$ (Fig.-5). Data were posted on respective data sheets. Tests were replicated for thirty times on each sample.

After completion of the procedure, data were collected and posted on data sheets. The statistical analysis was done for the test of significance.

Data were processed and analyzed using one way ANOVA with multiple comparisons facilitated by PostHoc Games-Howell Test. Here p value $<0.05$ was considered significant.

\section{Results:}

Both MTA and $\mathrm{Ca}(\mathrm{OH})_{2}$ were found to produce zone of inhibition against Staphylococcus aureus (ATCC 25923), Pseudomonas aeruginosa (ATCC 27853), Bacillus subtilis (BTCC 17 ), and Candida albicans (BTCC 493).(Fig 8) MTA showed highest activity against $S$. aureus and lowest activity against $P$. aeruginosa which was similar to the activity range of $\mathrm{Ca}(\mathrm{OH})_{2}$ against the mentioned organisms. But both of them failed to produce any activity against E. coli and. E. faecalis. MTA was found to produce a lower efficacy than $\mathrm{Ca}(\mathrm{OH})_{2}$ while comparing the zone of inhibition between them and statistically it was significant.

The findings of the study derived from data analysis are documented in tabular form (Table I- Table IV).

Table-I

\begin{tabular}{|c|c|c|}
\hline \multicolumn{3}{|c|}{$\begin{array}{c}\text { Efficacy of MTA and calcium hydroxide } \\
\text { on different microorganisms }\end{array}$} \\
\hline \multirow[t]{2}{*}{ Microorganisms } & \multicolumn{2}{|c|}{$\begin{array}{c}\text { Zone of inhibition }{ }^{\#} \\
\text { produced around holes (mm) }\end{array}$} \\
\hline & MTA & Calcium hydroxide \\
\hline S. aureus & 14.65 & 24.48 \\
\hline P. aeruginosa & 8.20 & 12.20 \\
\hline E. coli & 0 & 0 \\
\hline E. faecalis & 0 & 0 \\
\hline B. subtilis & 10.70 & 15.83 \\
\hline Candida albicans & 12.27 & 15.73 \\
\hline
\end{tabular}

\# Means of thirty times assays. 
Table-II

Compare of efficacy of MTA and calcium hydroxide on different microorganisms

\begin{tabular}{lccc}
. Microorganisms $^{\#}$ & \multicolumn{2}{c}{ Zone of inhibition produced around holes $(\mathrm{mm})$} & p-value $^{\#}$ \\
\cline { 2 - 3 } & MTA(n=180) & Calcium hydroxide $(\mathrm{n}=180)$ & \\
\hline S. aureus & $14.65 \pm 0.53$ & $24.48 \pm 0.61$ & $<0.001$ \\
P. aeruginosa & $8.20 \pm 0.25$ & $12.20 \pm 0.25$ & $<0.001$ \\
E. coli & 0 & 0 & - \\
E. faecalis & 0 & 0 & - \\
B. subtilis & $10.70 \pm 0.70$ & $15.83 \pm 0.69$ & $<0.001$ \\
Candida albicans & $12.27 \pm 0.45$ & $15.73 \pm 0.69$ & $<0.001$ \\
\hline
\end{tabular}

\# Data were analysed using Student's t-Test and were presented as mean \pm SD.

\section{Table-III}

Games-Howell Test for multiple comparisons in MTA group

\begin{tabular}{lcc} 
Comparing organisms $^{\#}$ & $\begin{array}{c}\text { Mean difference in zone } \\
\text { of inhibition (mm) }\end{array}$ & p-value* $^{*}$ \\
\hline S. aureus vs. P. aeruginosa & 6.45 & $<0.001$ \\
S. aureus vs. B. subtilis & 3.95 & $<0.001$ \\
S. aureus vs. C. albicans & 2.38 & $<0.001$ \\
P. aeruginosa vs. B. subtilis & -2.50 & $<0.001$ \\
P. aeruginosa vs. C. albicans & -4.07 & $<0.001$ \\
B. subtilis vs. C. albicans & 1.57 & $<0.001$ \\
\hline
\end{tabular}

\# Data were analysed using ANOVA statistics with multiple comparison facilitated by Post Hoc Games Howell Test; * The mean difference is significant at 0.05 level.

\section{Table-IV}

Comparison of zone of inhibition between MTA and Calcium hydroxide

\begin{tabular}{|c|c|c|c|}
\hline \multirow[t]{2}{*}{ Zone of inhibition(mm) } & \multicolumn{2}{|c|}{ Group } & \multirow[t]{2}{*}{ p-value ${ }^{\#}$} \\
\hline & $\begin{array}{c}\text { MTA } \\
(n=180)\end{array}$ & $\begin{array}{l}\text { Calcium hydroxide } \\
\qquad(\mathrm{n}=180)\end{array}$ & \\
\hline & $7.64 \pm 5.76$ & $11.38 \pm 8.89$ & $<0.001$ \\
\hline
\end{tabular}

\# Data were analyzed using Student's t-Test Test and were presented as mean \pm SD.

Table I shows that both MTA and Calcium hydroxide produced highest zone of inhibition against S. aureus But failed to produced any zone of inhibition against $\mathrm{E}$ coli and E faecalis.

Table II shows that In the culture media containing microorganisms like $S$. aureus, $P$. aeruginosa, $B$. subtilis and Candida albicans, the zone of inhibitions produced around the holes of MTA was observed to be significantly smaller than those produced around calcium hydroxide suggesting that the efficacy of calcium hydroxide is better than that of MTA on the four organisms ( $p<0.001$ in each case). However, neither calcium hydroxide nor MTA was found effective on

E. coli and E. faecalis as no zone of inhibition was found to be produced in the media containing culture of these two organisms. 
Table III demonstrates that antimicrobial efficacy of MTA was significantly better on $S$. aureus than that on $P$. aeruginosa, B. subtilis and Candida albicans, ( $<<$ 0.001). Again the efficacy of MTA was evident to be better on $B$. subtilis and Candida albicans compared to that on $P$. aeruginosa ( $\mathrm{p}<0.001$ ) with $B$. subtilis being more sensitive to MTA than Candida albicans $(\mathrm{p}<0.001)$.

Table IV compares the zone inhibitions produced around the holes in culture plates of irrespective of different microorganisms. The zone of inhibition produced around holes containing MTA was observed to be significantly smaller (7.64 \pm 5.76$)$ compared to that produced around holes containing calcium hydroxide $(11.38 \pm 8.89 \mathrm{~mm})$ irrespective of microorganisms $(\mathrm{p}<0.001)$.

\section{Discussion:}

In the present study both Mineral Trioxide Aggregate (MTA) and Calcium Hydroxide showed antimicrobial activity against $S$. aureus, $P$. aeruginosa, B. subtilis and C.albicans. The findings are similar to the findings of Sipert et al. ${ }^{8}$ who using similar methodology observed in vitro antimicrobial activity of MTA and calcium hydroxide based sealers (i.e. sealapex, fill canal, and Portland cements) against those organisms.

The reason for antimicrobial activity of MTA has been explained by the study of Duarte et $\mathrm{al}^{9}$ who demonstrated that the antimicrobial activity is seem to be related with elevated pH. Furthermore MTA contains calcium oxide, which when mixed with water; forms calcium hydroxide and induces an increase in $\mathrm{pH}$ by dissociation of calcium and hydroxide ions. An increase in $\mathrm{pH}$ level ( $\mathrm{pH}$ 12.5), creates an unfavorable environment for microbial growth ${ }^{10}$ because high $\mathrm{pH}$ is considered as bactericidal. Hydroxyl ions kill bacterial cells by damaging the cytoplasmic membrane, protein denaturation and damaging the DNA. Torabinejad et $\mathrm{al}^{11}$ observed an initial $\mathrm{pH}$ of 10.2 for MTA, rising to $12.5 \mathrm{in} 3 \mathrm{~h}$. The antimicrobial activity of calcium hydroxide may also be related to ionization with subsequent release of hydroxyl ions and an increase in $\mathrm{pH}$ levels ( $\mathrm{pH}$ 12.5). The antimicrobial activity of MTA-based materials against Candida albicans observed in the present study can also be explained by the sensitivity of this strain to high $\mathrm{pH}$. Al-Nazhan and Al-Judai ${ }^{12}$, demonstrated that at a stable concentration of $50 \mathrm{mg} / \mathrm{ml}$, white MTA was able to eliminate C. Albicans in vitro for up to three days.
Present study findings solely contradict with the study findings of Filho et al. ${ }^{10}$ who observed in vitro antimicrobial activity of Endodontic sealers, MTA based cements and Portland cement. They showed that all above mentioned organisms including E.coli and E. faecalis also inhibited by those materials. However, the difference between our study and the study of Filho et $\mathrm{al}^{10}$ may be due to using double layered agar plates and different concentration of microorganisms.

In the present study E. coli and E. faecalis were found to be resistant against the anti microbial activity of MTA and calcium hydroxide. Using agar diffusion method, Sipert et $\mathrm{al}^{8}$ while observing in vitro antimicrobial activity for sealapex, fill canal, Pro Root MTA, and Portland cements found no antimicrobial activity of MTA and Portland cement against E. coli. Ribeiro et $\mathrm{al}^{13}$ in an anaerobic condition, observed in vitro antimicrobial activities for MTA, calcium hydroxide and Portland cement; but found no antimicrobial activity against E. coli and E. faecalis. Miyagak et al ${ }^{14}$ also showed MTA and calcium hydroxide containing sealer have no antimicrobial effect against E.coi, E. faecalis etc with same methodology. Studies have shown that E. faecalis got killed only at a pH greater than 10-12 due to an inbuilt proton pump which enables it to survive in such alkaline environments ${ }^{15}$. The materials may also need direct contact with the bacteria for acting.

While comparing the antimicrobial activity of MTA and calcium hydroxide, although the mechanism of action of antimicrobial activity of MTA and calcium hydroxide is more or less same, in the present study, Mineral Trioxide Aggregate showed an antimicrobial activity lower than calcium hydroxide. This result is similar with previous study 8,10,13,16 This variation in antimicrobial activity between MTA and $\mathrm{Ca}(\mathrm{OH}) 2$ may be due to different diffusion and dissociation capabilities of two materials. Some substances have difficulty in dissociating and diffusing in agar (semi-solid medium), not expressing their real antimicrobial effect. ${ }^{17}$ A material that diffuses more easily will probably provide larger zones of microbial growth inhibition ${ }^{18}$. However, great care was taken to keep the plates for $1 \mathrm{~h}$ at room temperature to allow the diffusion the agents through the agar and then incubated.

Although used by many authors, differences in agar medium, diffusion capacity of inhibitory agents, bacterial 
strains and cellular density, as well as anaerobic atmosphere may interfere with formation of inhibition zones around materials used in antimicrobial testing. 8,13,16 However, there is not a consensus regarding to a gold standard test for the appraisal of antimicrobial testing of cements and other solutions used in dental therapy.

\section{Conclusion:}

According to the study findings, it can be concluded that MTA, though it was found effective against Staphylococcus Aureus, Pseudomonas aeruginosa, Bacillus subtilis, and Candida albicans; but it showed a lower efficacy than $\mathrm{Ca}(\mathrm{OH})_{2}$. On the other hand both MTA and $\mathrm{Ca}(\mathrm{OH})_{2}$ found inactive against E.coli and $E$. faecalis. So considering all these findings it can be recommended that for achieving asepsis in endodontic infection, $\mathrm{Ca}(\mathrm{OH})_{2}$ is preferable and should be used but continuing search should carry on to find out more effective material even against E.coli and E. faecalis.

\section{References:}

1. Vrcek D, Mehicic GP, Andrasevic AT, Guberina RP, Galic $\mathrm{N}$, Katunaric M. The antimicrobial effect of calacept, superlux, calcium hydroxide liner and gutta percha with calcium hydroxide. Acta Stoac Croat 2002; 36(2): 209-12.

2. Ingle JI, Simon JH, Machtou P, Bogaerts P. Outcome of endodontic treatment and re-treatment. In: Ingle JI, Bakland LK, editors. Endodontics. 5th ed. Hamilton Ontario (Canada): B.C.Decker Inc; 2002. p.747- 68.

3. Lee SJ, Monsef M, Torabinejad M. Sealing ability of a mineral trioxide aggregate for repair of lateral root perforations. J Endod 1993; 19(11):541-544.

4. Ford TR, Torabinejad M, McKendry DJ, et al. Use of a mineral trioxide aggregate for repair of furcal perforations. Oral Surg Oral Med Oral Pathol 1995; 79(6):756-763.

5. Shabahang S, Torabinejad M. Treatment of teeth with open apices using Mineral trioxide aggregate Pract Periodont Aesthet Dent 2000;12(3):315-320

6. Torabinejad M, Watson TF, Ford TR. Sealing ability of a mineral trioxide aggregate when used as a root end canal filling material. J Endod 1993; 19(12):591-595.
7. Rafter M Apexification: a review. Dental Traumatology 2005; 21: 1-8.

8. Sipart CR, Hussian RP, Nishiyama CK, Torres SA. In vitro antimicrobial activity of fill canal, sealapex, mineral trioxide aggregate, Portland cement and endoRez. Int Endod J 2005; 38: 539-43.

9. Duarte MA, Demarchi AC, Yamashita JC, Kuga MC, Fraga SC. $\mathrm{pH}$ and calcium ion release of 2 root-end filling materials. Oral Surg Oral Med Oral Pathol Oral Radiol Endod 2003; 95(3): 345-7.

10. Filho MT, Tanomaru JMG, Barros DB, Watanabe E, Ito IY. In vitro antimicrobial activity of endodontic sealers, MTA-based cements and Portland cement. J Oral Sci, 2007;49:41-45.

11. Torabinejad M, Hong CU, Pitt Ford TR, Kettering JD. antibacterial effects of some root end filling materials. J Endod 1995; 21(8):403-6.

12. Al-Nazhan S, Al-judai A. Evaluation of antifungal activity of mineral trioxide Aggregate. J Endod 2003; 29: 826-827.

13. Ribeiro CS, Kuteken FA, Hirata Jr R, Scelza MZ. Comperative evaluation of antimicrobial action of MTA, calcium hydroxide and Portland cement. J Appl Oral Sci 2006; 14(5): 330-3.

14. Miyagak DC, Carvalho EMOF, Robazza CRC, Chavasco JK, Levorato GL. In vitro evaluation of the antimicrobial activity of endodontic sealers. Braz Oral Res 2006; 20(4): 303-6.

15. Nageshwar RR, kidiyoor HK, Hedge C. Efficacy of calcium hydroxide- chlorhexidene paste against Enterococcus faecalis- an in vitro study. Endodontology, 2004; 16:61-64

16. Estrela C, Bammann LL, Estrela CR, Silva RS, Pecora JD. Antimicrobial and Chemical Study of MTA, Portland Cement, Calcium Hydroxide Paste, Sealapex and Dycal. Braz Dent J 2000; 11:3-9.

17. Estrela C, Pecora JD, Souza-Nito MD, Estrela CR, Bammann LL. Effect of vehicle on antimicrobial properties of calcium hydroxide paste. Braz Dent J1999; 10(2):63-72

18. Gomes BPFA, Pedroso JA, Jacinto RC, Vianna ME, Ferraz CCR, Zaia AA, Souza-Filho FJ. In vitro evaluation of the antimicrobial activity of five root canal sealers. Braz Dent J 2004; 15(1):30-35. 